\title{
UNIVERSUM
}

\section{ACTIVISMOS ARTÍSTICOS EN LAS MOVILIZACIONES CHILENAS RECIENTES: NUEVAS SOLIDARIDADES ENTRE EL ARTE Y LA CALLE $^{1}$}

\author{
Artistic activism in recent Chilean protests: new solidarities between art and street
}

\author{
María José Barros ${ }^{\mathrm{I}}$ (iD) \\ "Universidad Adolfo Ibáñez, Chile. mjbarroi@uc.cl
}

\section{RESUMEN}

A partir de las acciones artísticas desplegadas durante las movilizaciones posteriores al i8 de octubre de 2019 en Chile, en este artículo se proporcionan ciertos lineamientos para abordar los activismos artísticos actuales y la reformulación de los cruces entre arte y política. Se propone que el estallido social ha marcado un punto de inflexión con respecto al posicionamiento político asumido por diversos artistas chilenos, cuyas producciones e intervenciones públicas acerca de la contingencia nacional nos invitan a pensar la práctica artística como una plataforma colaborativa, creativa y de resistencia, desde la cual ejercer un agenciamiento político en el marco del Chile postdictatorial. Desde esta perspectiva, se analizan los trabajos de distintos creadores y colectivos en apoyo al movimiento social (Ana Tijoux, Mon Laferte, LASTESIS y Delight Lab, entre otros) y se propone una tipología para identificar las principales características de los activismos artísticos. PALABRAS CLAVE: activismo; artistas; espacio público; cuerpo; plataformas digitales.

\section{ABSTRACT}

Based on the artistic actions displayed during the protests following October I8, 2019 in Chile, this article provides certain guidelines for approaching current artistic activism and reshaping the crossovers between art and politics. It is proposed that the social unrest has marked a turning point in terms of the political stance adopted by different Chilean artists, whose productions and public interventions surrounding the national contingency situation call on us to contemplate artistic practice as a collaborative and creative platform of resistance, from which to exercise political agency within the framework of post-dictatorial Chile. From this standpoint, the works of different creators and groups in support of the social movement (Ana Tijoux, Mon Laferte, LASTESIS and Delight Lab, among others) are analyzed, and a typology is proposed for identifying the main characteristics of artistic activisms.

KEYWORDS: activism; artists; public space; body; digital platforms.

Fecha de Recepción $2020-03-30$

\section{Fecha de Evaluación} 2020-05-05
Fecha de Aceptación

$2 \mathrm{O} 2 \mathrm{O}-\mathrm{IO}-27$

${ }^{\text {I }}$ Este artículo se enmarca en el proyecto postdoctoral Fondecyt 3180228 "Artistas y activistas del siglo XXI: retóricas de la resistencia y genealogías descolonizadoras en Cecilia Vicuña, Ana Tijoux y Camila Huenchumil” (2018-2020), del que la autora es la investigadora responsable. 
Crear es un acto que incomoda. (Ana Tijoux)

\section{“CHILE DESPERTÓ”: A MODO DE INTRODUCCION}

Desde el I8 de octubre de 2019, Chile se encuentra viviendo un estallido social que ha venido a cuestionar los cimientos del sistema político-económico heredado de la dictadura de Pinochet y que en estos 30 años de transición democrática ha sido reforzado por los distintos gobiernos de turno. Movidas por un profundo descontento y malestar social, desde ese día miles de personas hemos caceroleado, participado en asambleas y salido a las calles para decir nuestra indignación frente a la mercantilización de los derechos sociales y la naturalización de los abusos de poder, pero también para denunciar las graves violaciones a los derechos humanos ocurridas en estos meses de protestas. Ha sido un tiempo luminoso y doloroso a la vez, en el que hemos sido testigos de la recomposición del tejido social que muchos creíamos totalmente atomizado luego de décadas de adoctrinamiento neoliberal. "Nos costó tanto encontrarnos, no nos soltemos", se lee en los muros de Santiago y también en las redes sociales. Y es que, efectivamente, la fuerza de lo colectivo ha vuelto a brotar con una enorme vitalidad y creatividad, visible en el despliegue de una serie de acciones artísticas que vuelven porosos los límites entre el arte y lo político, el arte y la calle, el artista y la comunidad y donde el papel de las plataformas tanto mediáticas como digitales ha sido crucial.

Al igual que en otros momentos históricos del acontecer nacional, diversos artistas se han solidarizado con las voces de la calle y han asumido como propias las demandas políticas del movimiento social en curso, que como bien sabemos se caracteriza por ser un movimiento transversal, acéfalo y al margen de las lógicas partidarias. Estamos hablando principalmente de músicos, actores, artistas visuales y performers, algunos ya consagrados y otros emergentes, cuyas producciones e intervenciones públicas en el marco de las movilizaciones actuales nos invitan a entender las prácticas artísticas como una plataforma colaborativa, creativa y de resistencia desde la cual ejercer un agenciamiento político. Pienso en cantautores como Ana Tijoux, Mon Laferte, Nano Stern o Alex Anwandter; colectivos de mujeres como LASTESIS, la Yeguada Latinoamericana o Memorarte; artistas callejeros como Caiozzama, Paloma Rodríguez o Fabciarolo; artistas multimediales como el colectivo Delight Lab; y el escultor Marcel Solar que dio vida al Negro Matapacos, por mencionar sólo algunos ejemplos. Son artistas que, de una u otra manera, han estado en primera línea poniendo el cuerpo y creando nuevas formas de protesta que 
reformulan, tensionan y complejizan los cruces entre arte y política desde los activismos artísticos que emergen en el Chile postdictatorial.

Por cierto, la presencia del activismo en la esfera del arte no es algo nuevo y, en el caso chileno, sus orígenes se pueden rastrear en los trabajos del Colectivo Acciones de Arte (CADA) o las Yeguas del Apocalipsis durante las décadas de los 70 y 8o. En este sentido, resulta importante aclarar que el activismo artístico se distancia del llamado arte de compromiso que movilizó a una parte importante del campo intelectual y artístico del siglo XX. ${ }^{2}$ Las relaciones entre el arte, lo político y la realidad social no se articulan en estas producciones más recientes desde los metarrelatos como el marxismo, las militancias partidarias ni la figura del intelectual paternalista que habla en nombre del "pueblo", sino que desde las luchas micropolíticas levantadas por distintos movimientos, comunidades y organizaciones sociales que comienzan a visibilizarse a partir de los 60 y 70 en contextos geopolíticos también diversos. Si hay algo que caracteriza a los artistas más jóvenes que se han involucrado con el movimiento social reciente es, justamente, su autonomía e independencia de los partidos políticos, su identificación con demandas relativas a reivindicaciones identitarias, y el trabajo territorial realizado en calles y poblaciones, pero también en los circuitos mediáticos y plataformas digitales.

En un contexto marcado por la creciente indignación de la población chilena frente a la precarización de la vida y el autoritarismo con que el gobierno de Piñera ha enfrentado las protestas, el estallido social ha marcado un punto de inflexión con respecto al posicionamiento político asumido públicamente por diversos artistas chilenos y en especial los de generaciones más jóvenes. De una u otra manera, la contingencia hizo que los artistas tomaran partido y solidarizaran con las demandas levantadas por el movimiento social en su lucha por la dignidad. Estamos hablando de demandas heterogéneas, que van desde el feminismo o la causa autodeterminista mapuche hasta una nueva constitución o el fin de las AFP, pero que a fin de cuentas se enmarcan en un cuestionamiento profundo a las políticas neoliberales del Chile (post)dictatorial y sus distintas formas de violencia: política, patriarcal, colonial, sistémica, etc. Considerando lo anterior, el objetivo de este artículo es proporcionar ciertos lineamientos que permitan abordar las manifestaciones de activismo artístico actuales a partir de ejemplos concretos y de manera situada,

\footnotetext{
${ }^{2}$ De acuerdo con Nelly Richard, el arte comprometido que existió en Chile antes de la dictadura se articulaba, fundamentalmente, desde la militancia partidaria de izquierda y la idea de que el artista debía "poner su creatividad al servicio del pueblo y la revolución" (Richard 2009). Como bien explica Nina Felshin, el activismo artístico es, efectivamente, un arte político al igual que el arte comprometido; sin embargo, este "no se concibe ya tanto como representación del sujeto de clase (a la manera del realismo social) sino como crítica de los sistemas de representación social (su posicionamiento respecto al género, los estereotipos étnicos, etc.). Tal transformación implica un cambio de posición y función del artista político" (97).
} 
es decir, tomando en cuenta las coordenadas geopolíticas que definen tanto su proceso de elaboración como recepción.

\section{¿QUÉ ES EL ACTIVISMO ARTÍSTICO?}

Antes de analizar los casos de activismo artístico que emergen durante el estallido social, resulta importante revisar algunos aportes teórico-críticos acerca de este concepto y su aplicación a prácticas artístico-culturales situadas en contextos históricos y culturales diversos. Para esto recurriremos al trabajo de autores como Nina Felshin, Chantal Mouffe, la Red Conceptualismos del Sur, Alberto López y Renato Bermúdez, entre otros, que nos permitirán articular una definición de activismo artístico acorde con las producciones chilenas que aquí nos interesa estudiar.

En su emblemático ensayo “¿Pero esto es arte? El espíritu del arte como activismo” (I995), Nina Felshin sitúa los orígenes del arte activista a mediados de la década de los 7o, en el marco de los movimientos por los derechos civiles, el feminismo, la revolución estudiantil y las protestas antibelicistas en Estados Unidos. En este clima marcado por el cuestionamiento a la autoridad y la emergencia de nuevas contraculturas, la curadora norteamericana define el activismo artístico como una "práctica cultural híbrida" situada entre el mundo del arte y el activismo político, que se caracteriza "por desafiar, explorar o borrar las fronteras y las jerarquías que definen tradicionalmente la cultura como tal y cómo ésta es representada desde el poder" (74). En coherencia con este afán por desdibujar todo tipo de límite y acercar el arte a un público más amplio, se produce -según Felshin- una unión entre el activismo político y las estéticas democratizadoras que encuentran su origen en el arte conceptual y su "tendencia a la desmaterialización" (Marchán Fiz 252). Estas propuestas se caracterizan por estar centradas en el proceso de creación artística, la participación activa del público, la circulación del arte más allá de los espacios institucionales y la apropiación de las técnicas de los medios de comunicación y la publicidad (Felshin 74). De ahí la importancia que tendrá la performance a fines de los 6o y comienzos de los 70 , práctica que fue valorada tempranamente por los conceptualistas y resignificada posteriormente por las artistas feministas y artistas activistas en general: "Los artistas activistas emplean actividades performativas por muchas razones, pero sobre todo porque su apertura e inmediatez invita a la participación pública" (Felshin 83). Aun cuando el arte conceptual celebrado actualmente en museos y galerías parece haber perdido aquella capacidad de impacto descrita por Felshin, rescatamos la idea del activismo artístico como una práctica híbrida, 
desafiante, democratizadora y colaborativa, que encontrará en la performance una de sus manifestaciones más radicales y emblemáticas hasta el día de hoy.

Siguiendo a la filósofa y politóloga Chantal Mouffe, el arte crítico o activismo artístico usa indistintamente ambas denominaciones- es aquel que promueve el disenso e impugna el consenso de las democracias actuales: "el arte crítico es el que fomenta el disenso, el que vuelve visible lo que el consenso dominante suele oscurecer y borrar. Está constituido por una diversidad de prácticas artísticas encaminadas a dar voz a todos los silenciados en el marco de la hegemonía existente" (2007: 67). En contra de las formas consensuales de democracia que hoy rigen a las sociedades occidentales, Mouffe (20II) aboga por la construcción de una democracia "agonista" en la que se reconozca abiertamente la dimensión antagónica constitutiva de "lo político", dando vida a un espacio público abierto a la discusión y el conflicto entre diferentes proyectos hegemónicos. Para la intelectual belga el espacio público es siempre un "campo de batalla" (2007: 64) y es ahí, precisamente, donde el arte activista interviene con todo su potencial disruptivo y cuestionador. Si bien no compartimos con Mouffe la idea de que el arte activista buscaría hablar por aquellos que supuestamente carecen de voz (subalternos los llamó Gayatri Spivak en su momento), sí estamos de acuerdo en que este tipo de prácticas más bien horizontales se caracterizan por poner en escena desde el lenguaje del arte- los discursos políticos y sociales disidentes, es decir, que cuestionan y subvierten el libreto oficial de los acuerdos. ${ }^{3}$ De esta manera, los artistas-activistas intervienen en el espacio público agonista y asumen un papel crítico que, por cierto, no está exento del riesgo de ser neutralizado o reciclado por los imperativos del mercado.

Por su parte, la Red Conceptualismos del Sur -centrada preferentemente en el estudio de las producciones activistas que emergen en los contextos de violencia autoritaria y dictatorial durante la década los 80 en América Latina- aboga por hacer una distinción entre arte activista y activismo artístico:

El concepto de "activismo artístico" surgió en el seno de la politización de la vanguardia europea de entreguerras. Lo preferimos al de "arte activista" porque, en este segundo, pareciera que el "activismo" es un adjetivo o un apellido del "arte", mientras que en aquél, es el activismo lo que prima permitiéndonos al tiempo tiempo subrayar la dimensión "artística" de ciertas prácticas de intervención social (43).

\footnotetext{
3 Desde la crítica literaria, Rubí Carreño también aborda la noción de disidencia para referirse a las manifestaciones artísticas que ponen en escena subjetividades que se enfrentan al biopoder ya no desde el lugar de la víctima, la ruina o la melancolía, sino desde la reivindicación del cuerpo, el placer, la libertad, la creatividad o el baile. Es lo que Carreño denomina biopoética: "Un disidente sería aquel que cotidianamente enfrenta y resiste creativamente a los poderes fáctico que lo consideran mano de obra, residuo o, desde el plano de la representación, "el otro". Dicho de otro modo, una biopoética es la respuesta artística al biopoder" (I4).
} 
Al privilegiar el uso del término activismo artístico, este grupo de investigadores busca poner de relieve la especificidad contextual latinoamericana y cómo las manifestaciones activistas regionales "anteponen la acción social a la tradicional exigencia de autonomía del arte" (43). Desde esta perspectiva, el activismo artístico es definido como aquellas producciones estéticas que, en situaciones militarizadas y represivas, se caracterizan por producir confrontaciones que reclaman una autonomía ya no con respecto a la esfera del arte, sino como un atributo de los sujetos y sus prácticas creativas en disputa con la institucionalidad política y cultural dominantes (44). En este sentido, los investigadores son claros al señalar que los activismos artísticos por ellos estudiados siguen siendo expresiones artísticas, pero que desbordan y amplían lo que tradicionalmente se entiende por arte y política.

En línea con el propósito de definir la particularidad de los activismos artísticos regionales, los académicos Alberto López y Renato Bermúdez centran su atención en las formas de activismo artístico que emergen durante las protestas latinoamericanas del siglo XXI, contexto marcado "por una profunda desigualdad económica y la erosión social provocada por las políticas financieras neoliberales" (24). Uno de los principales cambios que ambos autores advierten con respecto a los casos analizados por la Red Conceptualismos del Sur es que en las iniciativas más recientes -como Dale Letra en Venezuela o el Frente 3 de Fevreiro en Brasil- "su dimensión artística es "una cualidad emergente", es decir, que se produce en el desarrollo de sus actividades sin que sea definida así de antemano y, no obstante, singulariza sus modos de intervención” (27). A su juicio, en estas manifestaciones contemporáneas existe una "indiferencia ante las categorías y saberes artísticos especializados como una forma de orientar sus prácticas" $(27)$, rasgo que no se aplica a los activismos artísticos del estallido social abordados en este artículo. En los casos de Ana Tijoux, Delight Lab, LASTESIS o Caiozzama el arte sigue siendo el espacio desde el cual emergen sus producciones activistas; sin embargo, y siguiendo lo ya señalado por Felshin y la Red Conceptualismos del Sur, sus obras se articulan desde una desublimación de las prácticas artísticas y una clara disputa con las concepciones tradicionales, puristas y cerradas en torno al arte.

Por otro lado, no quisiera dejar de mencionar algunas visiones críticas en torno al activismo artístico, que ponen énfasis en las tensiones y contradicciones ideológicas de estas prácticas en relación con el mercado, la vida urbana y los movimientos sociales. A propósito de algunas intervenciones de "artivismo" realizadas en Barcelona en la década del 2ooo, pero también en otros países del mundo, el académico Manuel Delgado señala que asistimos a una "festivalización generalizada de la protesta" (77) que ha terminado por volverse útil a las políticas de promoción 
mercantil de las ciudades postmodernas. En este sentido, el investigador sostiene que algunas manifestaciones de arte activista se han convertido en una suerte show pospolítico banalizado por los medios de comunicación y las redes sociales, lo que finalmente terminaría por contribuir a "una atenuación de los efectos cuestionadores del combate social" (78). En pocas palabras, la posición de Delgado da cuenta de una mirada bastante escéptica frente al impacto real y efectivo de estas expresiones artísticas, problematizando así la sinergia entre arte y activismo político.

Tomando en consideración los aportes de los autores revisados previamente, quisiera proponer una definición general de activismo artístico desde la cual abordar los cruces entre arte y política en la escena cultural chilena reciente. Por cierto, esta definición se nutre también de otras lecturas teórico-críticas que serán incorporadas más adelante, así como del análisis de los trabajos artísticos que he realizado en estos últimos años de investigación y que, de una u otra manera, he podido corroborar al observar las acciones artísticas del movimiento social en curso. Sin más rodeos, propongo entender el activismo artístico como una práctica cultural fronteriza, disidente, colaborativa y de acción, que se caracteriza por vehiculizar discursos e imaginarios de transformación social afines a las preocupaciones de una comunidad situada en un contexto geopolítico específico y, al mismo tiempo, intervenir en las disputas de la esfera pública a través de nuevos lenguajes artísticos y plataformas masivas de difusión. A partir de esta definición y en consideración de las manifestaciones artísticos-culturales que surgen con el estallido social, en el próximo apartado desarrollaré las siguientes características que nos permitirán profundizar en el funcionamiento de los activismos artísticos contemporáneos: i) el artista-activista como agente mediático de cambios sociales; 2) el cruce entre disciplinas y la ocupación del espacio público; 3) la apropiación de tecnologías digitales y lenguajes masivos.

\section{TIPOLOGÍA PRELIMINAR}

\section{ARTISTAS-ACTIVISTAS COMO AGENTES MEDIÁTICOS DE CAMBIOS SOCIALES: TIJOUX Y LAFERTE}

¿Qué significa ser un artista-activista y cómo pensar esta categoría en el marco del estallido social? Para comenzar a responder esta pregunta, quisiera remitir brevemente al accionar de dos cantautoras chilenas durante las movilizaciones recientes: Ana Tijoux y Mon Laferte. Si bien ambas artistas se encontraban coincidentemente viviendo en el extranjero, ello no fue un impedimento para apoyar las demandas del movimiento social y denunciar las violaciones a los derechos humanos ocurridas durante los días de protesta. Al igual que otros artistas vinculados al 
movimiento, tanto Tijoux como Laferte recurrieron a los circuitos mediáticos y las redes sociales como plataformas de difusión de su pensamiento político y producción artística. Por ello propongo entender a los artistas-activistas del estallido como agentes mediáticos de cambios sociales, ${ }^{4}$ rol comunicacional asumido con distintos grados de visibilidad e impacto, que sin duda se complementa con el trabajo territorial realizado en calles, poblaciones y otro tipo de escenarios públicos.

En el caso de Tijoux, dos días después del estallido -el 20 de octubre de 20r9- la artista publicó en su cuenta de Instagram una primera versión de "Cacerolazo", cuyo video fue realizado con las grabaciones que distintas personas enviaron a la artista ante el llamado efectuado en sus redes sociales. Tal como su nombre lo indica, en esta canción la rapera reivindica el acto del caceroleo o cacerolazo, forma de protesta histórica ${ }^{5}$ que cobró fuerza a nivel nacional en cuanto el presidente Piñera decretó el estado de emergencia. Con el correr de los días, el video se viralizó (el uso del hashtag \#cacerolazo fue crucial) y la canción se convirtió en un himno de lucha del incipiente movimiento social. Ya estando en Chile, durante los meses de diciembre y enero, la cantautora realizó un trabajo territorial importante y participó en distintos eventos solidarios en apoyo a las víctimas de la represión policial. Junto con otros músicos se presentó el 26 de diciembre en Villa Francia, el 27 de diciembre en el concierto Por los ojos del pueblo y el 29 de diciembre se dirigió al velorio de Mauricio Fredes ${ }^{6}$ para rendirle un sentido homenaje con su canción "Calaveritas". A ello se suma su participación en la celebración de Año Nuevo realizada en la Plaza de la Dignidad, donde cantó en un improvisado escenario levantado en los balcones de las Torres Turri. Finalmente, el zo de marzo de 2020, Tijoux lanzó en Internet el video clip de "Antifa dance",

\footnotetext{
${ }^{4}$ Retomo la idea del activismo comunicacional y mediático del artículo de Giorgio Strafella y Daria Berg sobre Ai Weiwei, artista visual e intelectual chino cuya apropiación de la Web 2.0 -principalmente Twitter y su propio blog- lo ha llevado a convertirse en "a pioner among civil rights activists who look to the Internet for new channels of resistance and dissent" (I52). Si bien el uso de las plataformas digitales le ha permitido a Ai Weiwei soslayar la censura del régimen chino, los académicos plantean cierta inquietud sobre el impacto real de su activismo comunicacional más allá de los límites del mundo virtual: "His mode of activism, rich in communicative potential, is relatively poor in off-line action. [...] His bloggins and microbloggin may sow the seeds of the change he hopes for, but the effectiveness of communication activism is nonetheless limited insofar as it lacks offline, grassroots organisation and action, which is what the Chinese regime resists most strongly" (I5I).

5 En su artículo sobre las Jornadas Nacionales de Protesta (1983-1986) que tuvieron lugar durante la dictadura militar, Viviana Bravo analiza las distintas estrategias desplegadas por los sectores de oposición para manifestar su rechazo al régimen de Pinochet. Una de ellas fue, precisamente, tocar las cacerolas a una hora acordada previamente, acto de complicidad colectivo y anónimo que para muchos marcó un hito en la lucha contra la dictadura al romper "el disciplinamiento sonoro impuesto por los militares" (Bravo 133). De acuerdo con la académica chilena, esta forma de protesta histórica tiene un origen popular, que se remonta al golpeteo de cacerolas realizado por las mujeres de los mineros del carbón perseguidos por González Videla en 1947, y que luego fue imitado por las mujeres de clase alta en tiempos de la Unidad Popular (r34).

${ }^{6}$ Hombre de la primera línea que murió durante la manifestación del 27 de diciembre de 2019, luego de caer a un pozo electrificado mientras escapaba de la represión policial.
} 
canción inspirada en la revuelta de octubre en la que convergen elementos del rap, el reguetón e incluso la electrónica, y que constituye el primer adelanto de su próximo disco.

A diferencia de Tijoux, artista vinculada hace años a las luchas de distintos movimientos sociales y comunidades, Mon Laferte sorprendió a la audiencia nacional e internacional por su participación activa durante el estallido y su decisión de viajar a Chile para ser parte del movimiento. De regreso en el país, se unió tempranamente al colectivo El largo tour, iniciativa creada por un grupo de artistas y profesionales, quienes decidieron reunirse para cantar y acompañar a los pobladores de distintas comunas de Santiago y otras ciudades cercanas. Pero el hito más significativo y mediático fue, sin duda, su intervención en los Latin Grammy 2019, realizado el i4 de noviembre en Las Vegas, donde fue galardonada con premio al Mejor Álbum de Música Alternativa por su disco Norma. Además del discurso en contra de la represión policial dicho sobre el escenario, en la alfombra roja la cantautora hizo un uso político y performático de su cuerpo al exhibir en sus pechos un escrito que decía "En Chile torturan violan y matan", portando también el pañuelo verde por el aborto libre. Luego, al día siguiente, la artista dio a conocer en sus redes "Plata ta tá", canción en apoyo al movimiento que contó con la colaboración del rapero boricua Guaynaa. El video, estrenado el 5 de diciembre en la cuenta de Instagram de Laferte, obtuvo un millón de visualizaciones en tan solo doce horas. Por todo lo anterior, la cantautora chilena fue elegida por la BCC como una de las doce artistas que cambiaron el mundo el 2019. Además, durante su participación en el Festival de Viña del Mar 2020, Laferte aprovechó la popularidad internacional de este evento para seguir reforzando públicamente su compromiso con el movimiento.

A partir de los casos de ambas cantautoras y otros que han marcado el acontecer cultural del estallido, resulta posible sostener que los artistas, en su rol de activistas, son sujetos que buscan operar como agentes de cambio social y que conciben el espacio artístico como una plataforma de agenciamiento, resistencia y disidencia más allá de su terreno creativo. Son creadores que asumen públicamente un posicionamiento político y que confían en el potencial transformador de las prácticas simbólicas, es decir, en "la capacidad del arte de intervenir en zonas más amplias de resonancia pública" (Richard 2009). Lo interesante es cómo los artistas-activistas del estallido, al apropiarse de los circuitos mediáticos y las redes sociales para difundir masivamente sus discursos y obras, confieren a estas plataformas vinculadas principalmente a la información y el entretenimiento un carácter político movilizador. Por aquellos días, algunas canciones de Tijoux se convirtieron en hasthtag (\#lahorasono o \#doctrinadelshock) e incluso en grafitis, mientras que la 
imagen performática de Laferte en la alfombra roja de los Grammy dio la vuelta al mundo. Como bien señala Nathalie Goffard, con el estallido hemos asistido a una "reconversión misma del espacio virtual como coproductor y actor social, mediante el uso de dispositivos y emblemas del capitalismo globalizado". Efectivamente, las plataformas digitales han sido utilizadas de manera activa por el movimiento social como un medio alternativo de comunicación, organización y denuncia, y los artistas del estallido no han estado ajenos a ello.

Ahora bien, esta exposición mediática y viral por parte de algunos artistas ha sido cuestionada indirectamente por algunos de sus pares. Pienso, específicamente, en el artista visual Francisco Papas Fritas quien, en una de sus historias de Instagram publicadas a fines de 2019, preguntaba a los usuarios de esta red social qué es para ellos el "arte politizado". La respuesta "correcta" entregada por el artista visual era "capitalización individual del movimiento", aseveración que leo como una insinuación de oportunismo. La publicación de Papas Fritas deja entrever una mirada más bien crítica en torno a los artistas mediáticos movilizados políticamente y cierta sospecha frente a la posibilidad de disputar los espacios vinculados a la industria cultural y el mercado, tal como lo han hecho Tijoux y Laferte. Al respecto, no deja de ser relevante el hecho de que ambas cantautoras hayan recurrido a ritmos que coquetean con el reguetón para articular sus cantos de protesta, apropiándose de este género musical -ante todo festivo, pero también comercialmente exitoso- desde un posicionamiento abiertamente político. No por nada la revista Rolling Stones se refirió a la canción "Plata ta tá" de Laferte como un "perreo combativo" (Exposito) y "Cacerolazo" de Tijoux, por su parte, fue nominada en los Premios Pulsar 2020 como la Mejor Canción del Año. Todo pareciera indicar que, para ambas artistas, lo político no excluye el baile o la fiesta, ni tampoco la posibilidad de recurrir a formatos musicales masivos capaces de involucrar a una audiencia ampliada.

Por último, quisiera recalcar que los artistas-activistas también se caracterizan por establecer una relación más próxima con el público o al menos intentarlo. Ya no estamos hablando de los intelectuales que "debían hacerse cargo de una delegación o mandato social que los volvía representantes de la humanidad" (Gilman 59), sino de artistas que, en su condición de ciudadanos, buscan establecer una relación de horizontalidad y colaboración con una comunidad específica con la cual se identifican. No se piensan a sí mismos como los iluminados ni los portavoces que hablan desde una tribuna de superioridad intelectual. Por el contrario, los casos de Tijoux y Laferte, pero también de tantos otros, nos hablan de artistas que se conciben a sí mismos como un actor social más en la lucha por las transformaciones sociales y políticas que el país necesita, lo que además se 
condice con la ausencia de líderes y jerarquías al interior del movimiento que emerge con el estallido social. De ahí, también, la importancia del trabajo en/con/desde lo colectivo, donde muchas veces la figura del artista -entendida en su versión moderna, es decir, centrada en el "yo" o el individuo creador- se borronea en medio de un público cada vez más activo y participativo, capaz de intervenir en el proceso artístico con su propia voz y cuerpo.

\section{EL CRUCE ENTRE DISCIPLINAS Y LA OCUPACIÓN DEL ESPACIO PÚBLICO: COLECTIVO LATESIS}

Durante estos meses de movilizaciones, en la Plaza de la Dignidad y los lugares aledaños a este hito urbano de Santiago el activismo artístico se ha manifestado a través de distintas disciplinas, soportes y materiales: esculturas, arpilleras, bordados, performances, cantos, murales, ilustraciones, grafitis, fotografías e intervenciones lumínicas, entre otros. Parafraseando a Judith Butler en su libro Cuerpos aliados y lucha política, podemos decir que la calle se ha convertido en un espacio público y simbólico en disputa, donde los manifestantes ejercen su derecho a aparecer, es decir, a ser percibidos, vistos y oídos (87), a través de acciones creativas en las que se cruzan disciplinas heterogéneas y lenguajes vinculados tanto a la institucionalidad artística como a la cultura popular y los medios de comunicación masiva. Como bien explica la Red Conceptualismos del Sur, uno de los rasgos característicos de los activismos artísticos es la multiplicidad desde la cual se resignifica el concepto de arte, entendido como "el campo ampliado de confluencia y de articulación de prácticas "especializadas" (plástica, literatura, teatro, música...) y "no especializadas" (formas de invención y saberes populares, extrainstitucionales...)" (43). Con el estallido social, las jerarquías y fronteras entre los saberes artísticos, populares y mediáticos se han vuelto porosos, y la calle se ha transformado en el escenario predilecto de estas manifestaciones artístico-culturales de protesta.

En este contexto de ocupación y resignificación del espacio público, amenazado a su vez por la militarización de la ciudad y otras medidas represivas impulsadas por el gobierno de Piñera, la performance ha vuelto a emerger con fuerza, resituando los soportes del cuerpo y la calle como elementos fundamentales de la lucha política ejercida desde el arte. En su ya clásico Márgenes e Instituciones (1986), Nelly Richard identificaba "la elección del cuerpo y de la ciudad como materiales artísticamente desobedientes" (I8), utilizados por la Escena de Avanzada durante la dictadura para disputar la cotidianeidad social convertida en "escenarios de autocensura y microrepresión" (I8). Por otro lado, desde una lectura biopolítica y atendiendo a las intervenciones culturales de la era globalizada como Reclaim The Streets, Greenpeace y Critical Art Ensemble, entre otros, Lúcia Maciel Barbosa de Oliveira propone entender estas acciones performáticas como 
expresiones de resistencia en contra de las distintas formas de sujeción del poder, donde los "corpos indisciplinados em ação" (I65) ocupan un papel fundamental. En palabras de la académica brasileña: "O corpo é o locus principal da performance, lugar por excelência da experiência, arma poderosa em que a energia é concentrada para explodir intensamente" (I60). En el caso de las manifestaciones performáticas del estallido social, los cuerpos en cuanto soportes artísticos operan, justamente, como cuerpos desobedientes e indisciplinados, pero también como cuerpos aliados (Butler 2017) que irrumpen de manera creativa y colectiva en el espacio público para rebelarse en contra de las precariedades y violencias impuestas por el sistema político-económico vigente.

En términos concretos, pienso en las performances Libertarie (29 de octubre de 2019) del colectivo Maygara; Orden y patria (3r de octubre de 2019) del colectivo La Yeguada Latinoamericana dirigido por Cheril Linett; ${ }^{7}$ la acción de desnudo (24 de octubre de 2019) realizada por el colectivo Desperformance; Por un verano sin Piñera (25 de noviembre de 2019) de Rocío Hormazabal; Vulvas Acapella (24 de diciembre de 20I9) de la colectiva La Diosa Obscena; y, por cierto, Un violador en tu camino del colectivo LASTESIS, conformado por Lea Cáceres, Paula Cometa, Sibila Sotomayor y Daffne Valdés, cuya primera versión se realizó en la Plaza Aníbal Pinto de Valparaíso el 20 de noviembre de 2019. ${ }^{8}$ Más allá de la función expresiva y política de los cuerpos que estos trabajos intensifican, las performances del estallido coinciden en la denuncia de la violencia política como una violencia patriarcal ejercida sobre las mujeres y disidencias sexuales. En consecuencia, estas prácticas performáticas emergen desde un posicionamiento feminista y popular, que ha resituado las demandas del movimiento social y su cuestionamiento hacia el modelo neoliberal desde una mirada antipatriarcal. Por cierto, este cruce entre performance, cuerpo y feminismo encuentra sus antecedentes en las intervenciones de Diamela Eltit, Lotty Rosenfeld, Marcela Serrano y Paulina Humeres durante la dictadura (Cortés y Retamal 2017), pero también en acciones performáticas más recientes. Me refiero a aquellas que tuvieron lugar durante el llamado Mayo feminista de 2or8, cuando, en palabras de Olga Grau, "las jóvenes alteraron la cotidianeidad institucional [...] con gesto nuevos donde los cuerpos han sido un sustento político de rebeldía turbadora" (92). Como muchos recordarán, una imagen icónica de aquellos días fue la de una mujer con capucha roja y a torso desnudo parada sobre la estatua de Juan Pablo II en la Casa Central de la Universidad Católica, en un claro gesto de desobediencia hacia el sexismo de las instituciones académicas y el conservadurismo religioso.

\footnotetext{
7 En torno al trabajo performático de la Yeguada Latinoamericana y los cruces entre performance y feminismo, sugiero ver el artículo de Julieta Vásquez y Libertad Vidal publicado en la revista Index, específicamente, en el dossier Arte y Activismos en América Latina (2019).

${ }^{8}$ Gran parte de estas acciones han sido registradas por el productor digital Andrés Valenzuela Arellano, cuyas fotografías y videos se pueden encontrar en su cuenta de Instagram.
} 
Desde esta perspectiva, el caso del colectivo LASTESIS 9 durante el estallido ha sido, sin lugar a duda, paradigmático. El impacto y la repercusión de Un violador en tu camino, tanto a nivel nacional y latinoamericano como mundial, ha venido a reconfirmar el poder movilizador de las redes sociales, el protagonismo político de las mujeres y la masificación de prácticas artísticas como la performance. Efectivamente, esta es una acción que demanda la participación activa del público y que ha sido replicada, recreada y resituada por miles de mujeres en distintos países del mundo. En este sentido, las múltiples apropiaciones de esta performance y sus versiones en distintas lenguas (quechua, mapudungún, francés, inglés, italiano y turco, entre otras) dan cuenta de una concepción autorial basada en los principios de la colaboración y creación colectiva. De alguna manera, Un violador en tu camino ya no les pertenece del todo a LASTESIS, sino al colectivo de mujeres y disidencias que alrededor del mundo han hecho suya esta acción performática.

Además de la ola feminista que ha marcado el acontecer político de Chile en los últimos años, el éxito de la performance del colectivo LASTESIS se debe a que es un canto liberador, reparador y transgeneracional que ha permitido decir públicamente una experiencia de violencia compartida, desarticulando -al mismo tiempo- el discurso sobre la violación centrado en la idea del castigo moralizador ejercido sobre los cuerpos que problematizan el orden patriarcal. "Y la culpa no era mía, ni dónde estaba, ni cómo vestía", dice el estribillo de la canción. Lejos del terreno de la victimización, Un violador en tu camino es una acción que resitúa a las mujeres y disidencias sexuales en un lugar de empoderamiento y con voz propia, ${ }^{\text {Io }}$ desde el cual volver audible el reclamo contra la estructura patriarcal y el Estado como agente de la violencia política-sexual. Lo interesante es cómo este acto político se conjuga con decisiones artísticas que, como bien ha señalado Patricia Espinosa, dialogan con la estética del pop: "hay una musicalidad que me suena a pop, pero un pop revolucionario" (en Reyes). Todo en esta performance -la coreografía, la música, el vestuario y el texto, pero también su gestión y difusión a través de las plataformas digitales- ha confluido exitosamente en su masiva repercusión, sin perder por ello su potencial político y movilizador.

\footnotetext{
9 En una suerte de manifiesto sin título publicado en The Clinic, LASTESIS se definen como "un colectivo interdisciplinario de mujeres de Valparaíso que, a través de la performance y otros recursos sonoros, textiles, visuales; llevan a la práctica teorías feministas" (6).

${ }^{10}$ En Teoría King Kong, Virginie Despentes relata cómo después de leer a Camille Paglia cambió radicalmente su manera de vivir y pensar la violación, pasando del tabú y la culpa a la posibilidad de recuperar su vida activamente: "Ella era la primera que había sacado la violación del horror absoluto, de lo no dicho, de lo que no debe ocurrir nunca. Ella hacía de la violación una circunstancia política, algo que debíamos aprender a encajar. Paglia cambiaba todo: ya no se trataba de negar, ni de morir, se trataba de vivir con" (51 $)$. La mirada de Despentes acerca de la violación se encuentra alineada con la posición de empoderamiento promovida por LASTESIS.
} 
Pero hay algo más. Las primeras versiones de Un violador en tu camino en Chile fueron realizadas en espacios representativos del poder estatal y patriarcal. El zo de noviembre la primera intervención se hizo frente a la Segunda Comisaría de Carabineros de Valparaíso y el 25 de noviembre, Día Internacional de la Eliminación de la Violencia contra la Mujer, en la Plaza de Armas de Santiago, el Ministerio de la Mujer, el Museo Nacional de Bellas Artes y el Palacio de los Tribunales de Justicia, entre otros lugares. En este sentido, la acción de LASTESIS no sólo constituye una denuncia hacia las instituciones cómplices de la violencia de género, sino que también reivindica el derecho de las mujeres a ocupar el espacio público negado históricamente a las subjetividades vinculadas al mundo femenino. Como bien explica Rebecca Solnit en su texto dedicado al caminar, "Las mujeres han sido normalmente castigadas e intimidadas por intentar hacer efectiva la más simple de las libertades, salir a caminar, porque su caminar y, de hecho, todo su ser ha sido construido como algo inevitable y continuamente sexual" (354). Considerando lo anterior, podemos señalar que Un violador en tu camino es una performance que altera, desplaza y transgrede los límites de la territorialidad patriarcal impuestos sobre la base de los binomios público/privado, masculino/femenino. Los cuerpos reunidos no sólo se atreven a ocupar y resignificar distintos espacios de la ciudad, sino que además confieren un carácter público y político a un asunto tan grave como la violación, que por lo general suele ser tratado como un tabú o bien como un problema íntimo del que cada mujer debe hacerse responsable.

A partir del estallido social del i8 de octubre de 2019 las ciudades están siendo disputadas y sus diseños autoritarios cuestionados por el movimiento social. Los manifestantes se resisten a desocupar las plazas o abandonar las calles y muchas estatuas, representativas de la ideología patriarcal/militar/colonial sobre la cual se ha construido históricamente el Estado-nación chileno, han sido carnavalizadas y destruidas. ${ }^{\text {II }}$ En este contexto, participar en intervenciones artísticas como Un violador en tu camino significa atreverse a poner el cuerpo y sacar la voz, con todos los riesgos que ello implica. El activismo artístico, entonces, no puede ser pensado al margen del cruce entre distintas disciplinas y el potencial significativo que estos lenguajes impuros poseen, ni tampoco de la ocupación del espacio público -siempre corporal, disruptiva, desobediente- por parte de los artistas y ciudadanos que colaboran en estas acciones performáticas.

\footnotetext{
"Al respecto, sugiero consultar el artículo "Derribar símbolos coloniales: Un nuevo acto político que se suma en las protestas en Chile" de Paula Huenchumil, publicado el 8 de noviembre de 2019 en Interferencia.
} 


\section{LA APROPIACIÓN DE TECNOLOGÍAS DIGITALES Y LENGUAJES MASIVOS:} DELIGHT LAB

Durante el estallido social, las tecnologías digitales -en especial las redes sociales- han cumplido un papel fundamental como medios de comunicación alternativos. A través de Facebook, Twitter e Instagram, los usuarios que adhieren al movimiento han compartido videos para denunciar las violaciones a los derechos humanos silenciadas por la prensa oficial, pero además han organizado y difundido las convocatorias a las marchas, cabildos y cacerolazos. Al mismo tiempo, los artistas movilizados han privilegiado el uso de estas plataformas para dar a conocer sus trabajos, convocar al público y manifestar su posición frente a la contingencia. En este contexto, el caso de Un violador en tu camino ha sido emblemático. Estamos hablando de una performance que, si bien responde en primera instancia a un contexto de violencia política específico, se ha viralizado a escala mundial gracias a Internet. En consecuencia, podemos señalar que un componente esencial de los activismos artísticos actuales y los ciclos de protestas en los cuales se enmarcan es el uso político de las redes sociales, lo que bien podríamos entender a partir de la categoría de "multitud conectada" propuesta por Guiomar Rovira: "Estas movilizaciones no utilizan la tecnología como algo complementario, sino sinérgico. Lo que ocurre in situ y online son dimensiones imbricadas de un mismo fenómeno [...] Las personas que participan en las calles ya son cuerpos cyborgs, se manifiestan con sus extensiones tecnológicas incorporadas" (I37). En el caso del estallido chileno, las tecnologías digitales han sido utilizadas y apropiadas por el movimiento social como herramientas de difusión, organización colectiva, intercambio informativo y concientización, pero también, como veremos más adelante, como herramientas que han permitido crear registros y archivos autogestionados de los trabajos artísticos desplegados en el espacio público.

De la mano con lo anterior, también es importante señalar que los activismos artísticos se caracterizan por la utilización de lenguajes masivos inspirados en los medios de comunicación y la publicidad. En este tipo de manifestaciones culturales no sólo es importante el contenido del mensaje, sino ante todo su impacto. En este sentido, pienso que los activismos artísticos del estallido se articulan desde lo que Jonathan Harris ha llamado el globalismo utópico, es decir, expresiones artístico-culturales que sostienen creencias idealistas y de transformación del orden social, cuyas materializaciones físicas y visuales se encuentran ligadas a formas de representación y difusión de los medios de comunicación y el espectáculo (7-33). ${ }^{12}$ En el marco de las movilizaciones

\footnotetext{
I2 Un ejemplo paradigmático del globalismo utópico sería la performance Bed-in (1969) de John Lennon y Yoko Ono, artistas-activistas que hicieron circular su mensaje de paz en contra de la guerra y el imperialismo utilizando los medios de masas y estrategias publicitarias: "el 'Bed-in' ofrecía una crítica del orden social capitalista, pero al mismo tiempo participaba de él y contribuía a su espectáculo” (Harris 42).
} 
recientes, las intervenciones lumínicas realizadas por Delight Lab constituyen un ejemplo paradigmático. Desde que Piñera decretó el Estado de emergencia, el colectivo conformado por los hermanos Andrea y Octavio Gana ha estado proyectando sobre distintos edificios de Santiago y otras ciudades del país mensajes referentes a las demandas del movimiento social, la violación a los derechos humanos y el proceso constituyente, entre otras temáticas de interés público. ${ }^{13}$ De manera creativa, con un diseño depurado y textos contingentes capaces de condensar en pocas palabras la sensibilidad social y política del momento, los mensajes de Delight Lab son proyectados a gran escala en espacios abiertos visibles a la comunidad. "NO ESTAMOS EN GUERRA!" (Torre Telefónica, 2I de octubre de 20I9); "ÚNANSE AL BAILE DE LOS QUE SOBRAN" (Torre Entel, 8 de noviembre de 2019) o "NO TENGÁIS MIEDO DE JUZGARLO A ÉL!" (Palacio de los Tribunales de Justicia, io de diciembre de 2019), son algunos de los textos exhibidos por el colectivo durante el estallido, que dan cuenta de una discursividad intertextual y polifónica, es decir, habitada por múltiples voces y referencias culturales.

Aunque los primeros letreros de neón en Santiago datan de 1926 (Consejo de Monumentos Nacionales), la estrategia publicitaria de intervenir la ciudad con grandes carteles -muchos de ellos lumínicos- continúa vigente. Lo interesante es cómo el colectivo Delight Lab se apropia de este recurso afín al capitalismo con el objetivo de volver audible y visible un discurso político que, para decirlo en términos de Jacques Rancière (2006), viene a perturbar el "reparto de lo sensible" y situar en el centro del debate público y la ciudad las demandas de "los sin-parte" (7o). La luz se convierte así en un material artístico ${ }^{\mathrm{T} 4}$ que, al mismo tiempo, opera como un mensaje simbólico en sí mismo, pues se relaciona con la intención de volver visibiles e iluminar -y no lo digo en un sentido mesiánico- las voces que han sido históricamente silenciadas y marginalizadas de la sociedad chilena. De esta manera, los hermanos Gana han logrado ocupar y resignificar espacios emblemáticos de Santiago y otras ciudades del país, disputando su significado tanto público como

\footnotetext{
${ }^{13}$ Desde el ig de octubre hasta el 3i de diciembre de 2019, el colectivo ha realizado cerca de veinte proyecciones en total, emplazadas en Santiago, Valparaíso y Osorno. En su gran mayoría estas acciones consistieron en la proyección de textos, a excepción de dos trabajos que incorporaron otro tipo de elementos visuales. Me refiero a la intervención lumínica realizada en la Casa Central de la Universidad Católica el 25 de noviembre, donde se pudo observar la figura de Cristo con un ojo ensangrentado, en una clara alusión a las mutilaciones oculares perpetradas por la policía. También a la acción realizada en Osorno en defensa de las aguas, en la que se proyectaron mensajes en español y mapudungún e imágenes referentes a la cosmovisión mapuche. El video de esta intervención, titulado Ngen Ko, espíritus del agua, fue lanzado el 9 de enero de 2020.

${ }^{14}$ Estas acciones lumínicas encuentran su antecedente en las intervenciones públicas realizadas en dictadura por artistas como Alfredo Jaar, Diamela Eltit y Lotty Rosenfeld, así como en las obras de Raúl Zurita desplagadas en espacios abiertos que van desde el cielo al desierto de Atacama. En palabras de Octavio Gana: "Nos agarramos un poco del trabajo que hizo Raúl Zurita, entre otros, que trabaja la palabra mucho más allá de los libros: se va tomando la ciudad y el paisaje para poder extender el trabajo poético-artístico" (en Alonso). Más alla de la escena nacional, otros referentes importantes en el arte de la intervención lumínica son Jenny Holzer y Krzystof Wodiczko, artistas públicos que -de acuerdo con Daniel Makagon- realizan un uso alternativo de los medios "to mark urban space and disrupt every day life" (438).
} 
simbólico y soslayando los eventuales actos de censura que, lamentablemente, tuvieron lugar en el marco del confinamiento decretado en Santiago producto de la pandemia. ${ }^{15}$ Intevenir la Torre Telefónica con palabras como "DIGNIDAD" (ig de octubre de 2019) o expresiones de lucha en mapudungún como "MARRI CHI WEU" (3I de diciembre de 20I9) es una acción significativa y polémica, sobre todo si consideramos que este edificio es "un hito dentro del discurso desarrollista neoliberal impulsado por el empresariado durante la transición democrática" (alywen 79). El gesto, entonces, consiste en reescribir políticamente la ciudad, utilizando para ello los formatos masivos de la publicidad y también del diseño, pero desde la retórica del movimiento social.

Ahora bien, las obras intermediales de Delight Lab también se caracterizan por ser efímeras, intangibles y hasta cierto punto inmateriales. Por ello el registro de sus intervenciones lumínicas a través de la fotografía y el video resulta fundamental. En este contexto, las plataformas digitales han permitido al colectivo de los hermanos Gana y otros artistas del estallido construir archivos autogestionados para resguardar, almacenar y difundir su trabajo a un público más amplio y no presencial. Al mismo tiempo, gracias a las redes sociales, muchos de los trabajos realizados por estos artistas han sido registrados y viralizados por múltiples usuarios, lo que incluso nos permitiría hablar de la elaboración de archivos comunitarios. Además de las proyecciones de Delight Lab estoy pensando en las en las obras visuales de artistas callejeros como Caiozzama y Fabciarolo, pero también en los proyectos culturales Museo de la Dignidad, Museo del Estallido Social y La Ciudad Como Texto, cuyo objetivo es resguardar la memoria de las intervenciones artísticas y populares realizadas en los muros de la ciudad durante el estallido, mediante la elaboración de archivos digitales. ${ }^{16}$

Como bien señala Caiozzama, reconocido por sus ángeles renacentistas que portan letreros con consignas políticas, a partir del i8 de octubre de 2019 "muchos artistas han aparecido. Está lleno de muchos papeles, rayados, grafitis, una cosa que antes no se veía tanto. También hay mucha gente que está usando la técnica [paste up] que yo uso. Visualmente la calle está muy atractiva" (en Collao). Es justamente ese proceso de transformación de la calle en una plataforma artística y política abierta a la comunidad el que ha sido documentado, en gran parte, gracias a las tecnologías

\footnotetext{
${ }^{15}$ Sobre los actos de censura sufridos por Delight Lab y la declaración pública emitida por el colectivo, sugiero ver el artículo "Luz sobre luz: la censura a Delight Lab" de Francisco Villarroel, publicado en Artishock el 20 de mayo 2020.

${ }^{16}$ Resulta significativo reparar en que dos de estas instancias culturales utilicen la palabra "museo" para denominarse. Leo este gesto como una polémica o cuestionamiento hacia la institucionalidad del arte representada en este espacio de canonización, lo que a su vez se condice con los grafitis escritos en el Museo Nacional de Bellas Artes y Museo de Arte Contemporáneo durante el estallido, como por ejemplo "El arte para el pueblo", "Me meo en tu arte cuico" o "Muerte al arte capital y burgués". A fin de cuentas, estas acciones dan cuenta del agotamiento de una forma particular de hacer arte que, en el contexto de las movilizaciones, ha sido leída como una práctica elitista, despolitizada y mercantilizada encarnada en el museo.
} 
digitales, gesto que adquiere aún más relevancia después de que estas expresiones artísticas fueran brutalmente borradas. ${ }^{17}$ En este sentido, la idea sugerida por Pablo Vallejos acerca de la posibilidad de pensar los archivos digitales vinculados a la literatura y el arte en general como "un archivo cocreado, un anarchivo" (IIо) resulta iluminadora. Cuando hablamos de activismos y archivos, en especial de archivos digitales, estos también parecen operar -al menos en caso del estallido chileno- como un ejercicio de memoria y resistencia colaborativa, comunitaria.

\section{PALABRAS FINALES: "OJO CON OJO"18}

Desde que se iniciaron las movilizaciones en el marco del estallido social, más de zoo personas han sido víctimas de mutilaciones oculares perpetradas por agentes del Estado. Este hecho inédito en la historia reciente de nuestro país da cuenta de una violencia política brutal ejercida sobre los cuerpos y vidas de los manifestantes, mediante la cual se ha buscado reprimir y criminalizar el movimiento social en curso. Más allá del evidente daño físico y psicológico provocado por la represión policial, la herida inscrita en los ojos de los ciudadanos se condice simbólicamente con los actos de censura de ciertas acciones artísticas desplegadas durante el estallido. "Nos quieren ciegos", se leía hasta hace algunos meses en las inmediaciones de la Plaza de la Dignidad. Y es que, efectivamente, la intención autoritaria de disciplinar la mirada e higienizar la ciudad ocupada por los sujetos movilizados parece ser bastante evidente.

En este contexto de levantamiento popular, las nuevas solidaridades entre el arte y la calle se han entrelazado cada vez con más fuerza. Como hemos podido ver en las páginas anteriores, diversos han artistas se han unido al movimiento social en su lucha por la dignidad, asumiendo como propias las demandas políticas instaladas en el debate público. Desde esta perspectiva, nos propusimos analizar algunos casos de activismo artístico en el marco del estallido social, identificando al menos tres características que han definido la puesta en escena de estas producciones que, al igual que en otros momentos de la historia, han vuelto porosos los límites entre el arte y lo político. En primer lugar, definimos a los artistas-activistas involucrados en el estallido como agentes mediáticos de cambio social, es decir, son sujetos que creen en el potencial

\footnotetext{
${ }^{17}$ El ig de febrero de 2020, las fachadas del GAM y el Cine Arte Alameda amanecieron pintadas en un claro acto de censura; sin embargo, ese mismo día distintos artistas y voluntarios se reunieron para realizar un valioso trabajo de restauración que trajo de vuelta las principales imágenes, íconos y consignas del estallido. Al respecto, sugiero ver el artículo "Artistas y transeúntes vuelven a pintar las fachadas del GAM y el Cine Arte Alameda", de Catalina Mundaca y Francisco Oyarzún, publicado en Interferencia el 2I de febrero de 2020. Ahora bien, en el marco de la pandemia y el confinamiento, los muros de la ciudad han vuelto a ser borroneados, gesto que recuerda la higienización violenta de la ciudad impulsada por los militares en los días posteriores al golpe de Estado de 1973.

${ }^{18}$ Retomo esta frase de la performance El veroir empezó de Cecilia Vicuña, realizada el i4 de diciembre de 2019 en el GAM.
} 
transformador de las prácticas simbólicas y que han recurrido a los circuitos mediáticos y digitales para difundir sus creaciones en apoyo al movimiento y dar a conocer su postura acerca de la contingencia política. A partir de los casos de cantautoras como Tijoux y Laferte, observamos también cómo los artistas-activistas han disputado los espacios de la industria cultural y el mercado para vehiculizar sus mensajes y llegar a un público más amplio.

En segundo lugar, señalamos que los activismos artísticos del estallido social se han caracterizado por desafiar las fronteras entre los saberes artísticos, populares y mediáticos, a través de la creación de lenguajes impuros y mixtos que admiten el cruce entre distintas disciplinas, soportes y materiales. Desde esta perspectiva, el cuerpo y la calle han vuelto a emerger con fuerza como elementos fundamentales de la resistencia política ejercida desde el arte. Lo anterior se observa especialmente en las múltiples performances realizadas e impulsadas por colectivos feministas en distintos espacios públicos de Santiago y otras ciudades del país, acciones que han vuelto visible la violencia patriarcal del Estado ejercida sobre las mujeres y disidencias sexuales. En este contexto, analizamos Un violador en tu camino de LASTESIS, acción performática que se ha viralizado y replicado en distintos lugares del mundo, posibilitando que los cuerpos indisciplinados de las mujeres alteren la territorialidad patriarcal con un canto liberador, reparador y transgeneracional acerca de la violencia de género.

Por último, analizamos cómo los activismos artísticos del estallido se han apropiado de las tecnologías digitales y los lenguajes masivos para amplificar el impacto de sus obras. Tal es el caso del colectivo Delight Lab, cuyas proyecciones lumínicas emplazadas preferentemente en la Torre Telefónica constituyen un gesto de reescritura política de la ciudad, que se realiza recreando los formatos de la publicidad y el diseño, pero desde la retórica del movimiento social y el influjo de otros artistas que también han recurrido a la luz como material artístico para irrumpir en el espacio público. Además, observamos que el uso de las redes sociales por parte los artistas y sujetos movilizados ha permitido crear archivos digitales comunitarios y autogestionados, en los que se resguarda la memoria visual del estallido.

Considerando lo anterior, podemos señalar que si bien los activismos artísticos del estallido aquí analizados encuentran sus antecedentes en las acciones de arte realizadas en dictadura por el CADA (Neustadt 20oI) y las Yeguas del Apocalipsis, así como en las nuevas formas de protesta festiva del movimiento estudiantil del 20II (Carreño 20I3) y el Mayo feminista del 2or8, estos poseen ciertas particularidades que, más allá de lo contextual, se relacionan con una revitalización de la experiencia de lo colectivo. El movimiento en el que se sitúan estas 
manifestaciones artísticas ha logrado como nunca en estos últimos zo años convocar a amplios y diversos sectores de la sociedad chilena, que han salido masivamente a las calles para expresar su malestar e indignación frente a las políticas neoliberales que han precarizado las vidas de los chilenos. ${ }^{19}$ En este sentido, lo que quisiera proponer es que la heterogeneidad y transversalidad de este movimiento se condice con la experiencia de lo colectivo en la que se sostienen los activismos artísticos actuales y desde la cual se están reformulando los cruces entre arte y política.

Entre los artistas movilizados resulta cada vez más predominante el trabajo en colectivos o bien de la mano con organizaciones sociales territoriales. En línea con lo anterior, las acciones desplegadas por estos artistas dan cuenta de una práctica de resistencia que se piensa y ejecuta de modo colaborativo, donde los ciudadanos ocupan un papel cada vez más activo y protagónico. Pienso en los sujetos que viralizan estas acciones en sus redes sociales, los manifestantes que participan de las performances e incluso las convocan, así como en aquellos que forman cordones de seguridad para que estas intervenciones sean desarrolladas sin inconvenientes en la vía pública. Todo lo anterior nos remite a una forma autogestionada de hacer arte, que se entrelaza estrechamente con lo colectivo, y donde las relaciones entre artista y comunidad -una comunidad diversa, fraterna, interconectada y movilizada políticamente- se vuelven cada vez más próximas. De una u otra manera, el estallido ha visibilizado una escena artístico-cultural que no solo se identifica y solidariza con el movimiento social, sino que además promueve formas de participación más horizontales, colaborativas, democráticas e inclusivas. De ahí la relevancia de los activismos artísticos en estos tiempos de disputa y redefinición del pacto social vigente.

\section{REFERENCIAS}

Alonso, Carla. "Entrevista a Octavio y Andrea Gana, creadores de Delight Lab: 'No nos acomoda estar en espacios de elite". Culturizarte. 9 abr 2020. https://cutt.ly/5RoUsdO

Alywen. "\#RenunciaPiñera. Arte chileno urgente durante estado de excepción". Los futuros imaginados. Editores Fernando Gaspar y Guillermo Jara. Santiago: Vicerrectoría de Investigación y Desarrollo Universidad de Chile, 2020.

Barbosa de Oliveira, Lúcia Maciel. Corpos Indisciplinados. Ação cultural em tempos de biopolítica. São Paulo: Beca, 2007.

Bravo, Viviana. "Etnografía histórica de la protesta urbana: las Jornadas Nacionales contra la dictadura, Santiago de Chile, I983-1986". Revista Antropologías del Sur I2 (2019): I29-I48. ${ }^{19}$ La marcha del 25 de octubre de 2019 , que reunió a más de un millón doscientas mil personas en la Plaza de la Dignidad,
es un claro ejemplo de ello. 
Butler, Judith. Cuerpos aliados y lucha política. Hacia una teoría performativa de la asamblea. Trad. María José Viejo. España: Paidós, 2017.

Carreño, Rubí. Av. Independencia. Literatura, música e ideas de Chile disidente. Santiago: Cuarto Propio, 2013.

Collao López, Valentina. "Caiozzama: "La calle se transformó en el lienzo de los que quieren decir algo" (Entrevista). The Clinic. 2I de noviembre de 2019. Disponible en: hetps://cutt.ly/oRoUlro

Consejo de Monumentos Nacionales. "Letrero publicitario de "Valdivieso"'. Consejo de Monumentos Nacionales. Disponible en: https://cutt.ly/XRoUz88

Cortés Picazo, Luis Claudio; Retamal Ruiz, María Elena. "Irrupción postfeminista en Chile a través de las artes visuales y la performance". Universum 32 (2) (2017): 29-45. http://dx.doi.org/10.4067/S0718-23762017000200029

Delgado, Manuel. "Artivismo y pospolítica. Sobre la estetización de las luchas sociales en contextos urbanos". Quaderns-e i8 (2) (2013): 68-80.

Deligh Lab. Instagram, I9 de diciembre 2019 - 9 de enero 2020. Disponible en: https://www.instagram.com/delight_lab/

Despentes, Virginie. Teoría King Kong. Trad. Paul B. Preciado. Santiago: Penguin Random House, 2018.

Exposito, Suzy. "Mon Laferte, Guaynaa Lead Reggaeton Protest in New 'Plata Ta Tá' Video". Rolling Stone. 6 de diciembre de 20r9. Disponible en: https://cutt.ly/URoUYBc

Felshin, Nina. “¿Pero esto es arte? El espíritu del arte como activismo”. Modos de hacer: arte crítico, esfera pública y acción directa. Trad. Paloma Blanco. Eds. Paloma Blanco, Jesús Carrillo, Jordi Claramonte y Marcelo Exposito. Salamanca: Ediciones Universidad de Salamanca, 200I.

Gilman, Claudia. Entre la pluma y el fusil. Debates y dilemas del escritor revolucionario en América Latina. Buenos Aires: Siglo XXI, 2012.

Goffard, Nathalie. "La revolución de los celulares, o la apropiación como imaginario actual". Artishock. 2I ene 2020. Disponible en: https://cutt.ly/ZRoUPYJ

Grau, Olga. "Un cardo en la mano". Mayo feminista. La rebelión contra el patriarcado. Ed. Faride Zerán. Santiago: LOM, 2018.

Harris, Jonathan. Los globalistas utópicos. Artistas de la revolución mundial 19r9-2009. Trad. Joaquín Chamorro Mielke. Madrid: Akal, 2016.

LASTESIS. "Un violador en tu camino". The Clinic № 826, jueves 66 de octubre 20r9. (Impreso).

LASTESIS. Sin título. The Clinic № 826, jueves 66 de octubre 2019 (Impreso). 
López Cuenca, Alberto; Bermúdez Dini, Renato David. “Pero esto qué es? Del arte activista al activismo artístico en América Latina, 1968-2018”. El ornitorrinco tachado 8 (2018): 17-28. https://cutt.ly/2RoUHZe

Makagon, Daniel. "Accidents should happen: cultural disruption through alternative media". Journal of Communication Inquiry 24 (4) (2000): 430-447.

Marchán Fiz, Simón. "Del arte objetual al arte de concepto (I960-1974). Epílogo sobre la sensibilidad "postmoderna". Madrid: Akal, 20 Iо.

Mouffe, Chantal. "Prácticas artísticas y política democrática en una era pospolítica". Prácticas artísticas y democracia agonística. Barcelona: Museu d'Art Contemporani de Barcelona, Servei de Publicacions de la Universitat Autònoma de Barcelona, 2007.

Mouffe, Chantal. En torno a lo político. Trad. Soledad Laclau. Buenos Aires: Fondo de Cultura Económica, 20II.

Neustadt, Robert. CADA DÍA: La creación del arte social. Santiago: Cuarto Propio, 20or.

Rancière, Jacques. Política, policía, democracia. Traducido por María Emilia Tijoux. Santiago: Lom, 2006.

Red Conceptualismos del Sur. Perder la forma humana. Una imagen sísmica de los años ochenta en América Latina. Catálogo de exposición. Madrid: Museo Nacional Centro de Arte Reina Sofía, 2012.

Reyes, Romina. "Performances en el estallido: La otra forma de protestar". The Clinic. 2 de enero de 2020. Disponible en: https://cutt.ly/fRoUVPT

Richard, Nelly. Márgenes e instituciones. Arte en Chile desde I973. Santiago: Metales Pesados, 2014.

Richard, Nelly. "Lo político en el arte: arte, política e instituciones". e-misférica 62 (2009). Disponible en: https://cutt.ly/yRoUMQa

Rovira Sancho, Guiomar. Activismo en red y multitudes conectadas. Comunicación y acción en la era de Internet. México: Icaria Editorial; Universidad Autónoma Metropolitana, 2017. https://cutt.ly/FRoU3Dv

Strafella, Giorgio; Berg, Daria. "Twitter Bodhisattva": Ai Weiwei's Media Politics". Asian Studies Review I (39) (2015): I38-I57. https://doi.org/Io.Io80/I0357823.20I4.990357

Solnit, Rebecca. Wanderlust. Una historia del caminar. Santiago: Hueders, 2015.

Vallejos Baccelliere, Pablo Ignacio. "El archivo digital como objeto de estudio para comprender mecanismos de subjetivación que ocurren en la red". $45^{\circ}{ }^{\circ} \mathrm{F} 23$ (2020): IO2-I2O. 